folk/ed. 2021; 27(2) $106 \mathrm{Ek}$

DOI: $10.22559 /$ folklor.1533

\title{
Tween/Eşikergen Jargonu "Mean Girls" ve Güzellik Zorbalığı*
}

Tween Jargon "Mean Girls" and Beauty Bullying

\section{Ebru Güzel ${ }^{* *}$}

\section{Öz}

Ataerkil ideolojinin kadınlara dayattığı dış görünüşe bağımlılık, gösteriş, özseverlik ve rekabetçilik gibi yıkıcı duyguların kız çocuklarını da esir alması, yasal olmamasına rağmen 13 yaşın altındaki çocukların Instagram'da, şimdilik 2 milyon "tween/eşikergen" etiketi altında yetişkin görünümlü paylaşımlarda bulunması, güzellik siber zorbalığının artışı ve sosyal medyada kullanılan kelime ve söz öbeklerinin konuşma diliyle etkileşime geçmesi eşikergen sorunlarının başında gelmektedir.

Bir nitel araştırma yöntemi olarak gömülü teori ve derinlemesine görüşmelerin kullanıldığı bu çalışmada, güzellik zorbalığı, Mean Girls filmiyle tanımlanmakta, sosyal medyada açıkça görülebilen "eşikergen jargonu” konuşma diline yansımaktadır. Örneğin çocukların çevrimiçi alanlarda kullandıkları

Geliş Tarihi (Arrived): 7.11.2020 - Kabul Tarihi (Teceived): 12.03.2021

* Bu makalede, saha araştırması kapsamındaki görüşmeler TR Dizin kriterlerinin Etik kurallarla ilgili maddelerinin uygulanması zorunluluğu getirilmesinden önce, 2018-2019 tarihleri arasında gerçekleştirilmiştir. Aynı saha çalışması sırasında elde edilen ancak makalede kullanılmayan verilerin geniş bir bölümü, yazarın 2019 yılında yayınlanan ve ilgili çalışmada da kaynak olarak gösterilen Eșikteki Cocuk \#tween adlı kitabında yer almaktadır.

** Doç. Dr., Fenerbahçe Üniversitesi İletişim Fakültesi, Yeni Medya ve İletişim Bölümü. ebru.guzel@fbu.edu.tr. ORCID 0000-0001-7029-1761 
“taglemek", "beğeni yağdırmak", "ss/dm atmak", "karşim”, "feno", “efso", gibi sözcükler ve kısaltmalar günlük dilde de kullanılmaktadır. Sonuç olarak eşikergen jargonunun çocukların yaşam biçimiyle ifade bulması, güzellik siber zorbalığının, rekabetin ve yarışın artmasıyla birlikte bu yeni kız çocuğu kültürünün dil yozlaşmasını da görünür kıldığı tespit edilmiştir. Ayrıca çalışmanın sadece dil yozlaşmasını değil, çocukluğun yozlaştığını göstermesi bakımından da alanyazına katkı sağlayacağı öngörülmektedir.

Anahtar sözcükler: eşikergen, güzellik zorbalığl, güzellik siber zorbalığl, eşikergen jargonu, dil yozlaşması

\begin{abstract}
The destructive emotions imposed on women by patriarchal ideology, such as dependence on appearance, vanity, narcissism, and competitiveness are also capturing girls; children under the age of 13 sharing adult-looking posts on Instagram under 2 million "tween" tags although it is illegal; cyberbullying and the words used in social media and the interaction of phrases with spoken language are the main problems of tween. In this study, grounded theory and in-depth interviews are used as a qualitative research method, beauty bullying is defined with the movie Mean Girls, and the "tween jargon" that can be clearly seen in social media is reflected in the spoken language. For example, words and abbreviations used by children such as tag, "break my scale", "send ss/dm", "bro/sis", "feno", "efso" are also used in daily language. As a result, the expression of tween jargon with the way of life of these children determines the increase of beauty cyberbullying, competition and language degeneration of this new girl culture. In addition, it is predicted that this study will contribute not only to the corruption of language but also literature in terms of childhood degeneration.
\end{abstract}

Keywords: tween, beauty bullying, beauty cyberbullying, tween jargon, corruption of language

\title{
Extended summary
}

Background: "Tween", usually used for children between the ages of 8 and 13, is simply defined as "child on the threshold".

On Instagram, girls exist with adult-looking posts undertween hashtag in -at least- two million people. The posts contain usually the admiration of the tweens, to beauty, to fashion, to luxury life and to celebrity. "Mean girl", which was defined by the research sample as being influenced from the movie Mean Girls, means beauty bully. As we search the jargon of mean girl, the words used by tweens in the digital world, abbreviations, Turkishized words, words with changed meaning, syllable added/reduced words and speech disorder words are used in daily language. Factors that threaten linguistic integrity were also investigated in the search for beauty bullying through tween jargon. In the background of the research, tween jargon, beauty bullying and beauty cyberbullying are discussed with current resources. 
According to We Are Social (2020) findings, Turkey is the sixth (38 million) in Instagram usage in the world, so this makes the research remarkable. When tween and teen accounts are observed, it can be seen that the increase in the use of Instagram in Turkey in recent years is due to children. In this study, as a result of combining different sources, the relationship of tween phenomenon with beauty bullying and language degeneration has been tried to be revealed.

Methodology: In this study, a theory was formed by using the data obtained from the research sample. Hence in study, grounded theory and in-depth interviews are used as a qualitative research method, beauty bullying is defined with the movie Mean Girls and the tween jargon that can be clearly seen in social media is reflected in the spoken language.

The research started in March 2018, it took one year in the intermittent observation and examinations due to developments in fieldwork. Via purpusive sampling face-to-face interviews were conducted with 22 girls aged 8-13. This research focused on two interrelated problems. The use of beauty bullying and tween jargon, expressed in the jargon of mean girls between tween girls, has been questioned as a result of language degeneration.

Research Purpose: In this study, it was aimed to investigate the beauty bullying problem that emerged with the jargon of mean girl and the digital jargon reflected in the spoken language of tweens. It is also though that resarching "new girl culture" will create a social benefit. In addition, determining the disappearance of childhood through language opens the question of "what kind of future awaits children".

Findings: Based on the words used by tweens, the findings are presented under 4 headings: 1) "Mean girls": Plastics, queen bee and victim, 2) "Break my scale": "Gush likes buddy", "tag me karşim (bro/sis)", 3) "Doom günüsü (short for birthday)" fans, 4) "Efso (short for legend)", "popi (short for popular)" and "feno (short for phenomenon)".

According to the research findings, bully, popular, phenomenon, attractive and beautyobsessed girls at school were defined as "mean girl". Characteristics that tweens describe bully peers in their own school overlap with Plastics in the movie Mean Girls. All of the participants expressed that they had problems with their girlfriends, a tween had to leave the school. Tweens who suffer from beauty cyberbullying on social media are punished through applications such as like, comment, follow.

"Brake my scale" jargon is not used in the Instagram correspondence of tweens in Turkey, but the word "like" is used obsessively. As a matter of fact, in the findings, this desire was expressed verbally with the jargon of "gushing likes". In addition abusive words such as "AMK (fck)" are also used. Tween posts are aesthetic, filtered, beautiful and flawless. Break my scale is like an expression of this ambition, because celebrity is marketed as a profession in social media. Tweens in this spiral have to achieve a certain standard of beauty, whether for social approval or to achieve the phenomenal dream.

In the tween group, birthday parties and especially guest lists are seen as another form of expression of bullying. It is aimed to hurt the victim by not inviting her to a popular party. Tweens exemplify the wrong use of language with the phrase "doom günüsü (short for 
birthday)". In addition, the evil, cynicism and tyranny that infects beauty are hidden by the "popi/popu(lar)" camouflage; good and evil are interchanged.

Results and conclusions: Tweens whom Instagram usage rates in Turkey are thought to increase, are also seen to use digital jargons in daily language. This language is associated with the concepts of beauty, beauty bullying, beauty cyberbullying, narcissism and celebrity. The ideal of being "pheno(menon)", "lege(nd)" or "popu(lar)" is normalizing, tweens are left in limbo at an age that is very vulnerable to biological, hormonal or psychological effects.

It should not be forgotten that a victim who suffers from beauty bullying can also be a bully. In this new girl culture, where power and success are tied to being a social media phenomenon, even an ordinary birthday party can turn into a bully. As a result this research reveals that not only language but also childhood is degenerating. The "ideal girl", wrapped in an almost adult package of flawless beauty, fashion, brand, fame and luxury life, incentivizing via social media. While exploiting tween bodies with patriarchal ideology, social media and tween market cooperation, it is necessary to discuss the significant number of accounts managed by mothers.

\section{Giriş}

Genel olarak 8-13 yaşları arasındaki çocuklar için kullanılan tween kavramı bir pazarlama stratejisi olarak doğmuştur (1). Türkçeye "eşikergen” olarak çevrilen tween, en basit ifadeyle ne çocuk ne de ergen, ara bir konumu anlatmaktadır (2). Kavramın belirsiz bir evreye denk düşmesi, onu eşik ile betimlemeyi mümkün kılarken buradaki ergen sözcügüule de tween ile anlatılmak istenilen vurgulanmaktadır: "Yetişkinleştirilen çocuk". Kesinlikle çocukluk kategorisi içinde değerlendirilmesi gerekirken, eşikergenlerin sosyal medyada her yıl milyonları bulan paylaşımları pek çok sorunu gözler önüne sermektedir. Eşikergen olgusunun işaret ettiği sorunlardan biri de dilin kullanımıdır.

Güncel yazında eşikergenlerin kullandığı sözcüklerin anlamını açıklayan pek çok internet haberi bulunmaktadır. Örneğin aile/familiy "fam", aman tanrım/oh my God "OMG", "ölçeğimi kır/break my scale BMS”, bebek/babe "BB”, erkek arkadaş/boyfriend " $B F$ " ya da ailem izliyor "9" gibi kısaltmalarla ifade bulmaktadır. Eşikergen mesajlaşmalarında genellikle kolaylık sağladığı için yer verilen kısaltmalar, bozulan ya da uydurulan yeni sözcükler konuşma diline de dahil edilmektedir. Örneğin iletişim kurarken yüksek sesle kahkaha atmak anlamına gelen "LOL” (laughing out loud), bir internet kısaltması olarak günlük konuşmaya geçen en yaygın sözcüktür (Obenschain, 2020). Tam da bu noktada argo, kaba dil, jargon ve küfür arasındaki tanım farklılıkları ile eşikergen jargonunun bu hassasiyete göre değerlendirilmesi gerekliliği öne çıkmaktadır. Bir jargonun belirli bir grubun sınırlarını aşmasıyla argoya dönüşmesinden farklı olarak, burada hiçbir kurala uyulmadan Türkçeleştirilen, çarpitılan ya da uydurulan sözcüklerin ana dile geçmesi söz konusudur. Dolayısıyla eşikergen jargonunu araştırmak, dil bütünlügünü tehdit eden faktörleri görmek açısından da önemlidir.

Sosyal medya kullanımında dünya sıralamasına giren Türkiye’de, aslında bu 
oransal başarının çocukların açtığı hesaplarla yakalandığı düşünülmektedir. Küresel ölçekte sosyal medya bağımlılığının kültüre ve dile etkisi yıkıcı olmuştur. Dijitalleşme, yabancılaşma, bireyselleşmenin ve metalaşmanın çocukları da kapsadığı bir çağda dil de nasibini almaktadır. Araştırma bulgularında güzellik zorbalığını tanımlayan Mean Girls filmi; dolayısıyla "mean girl" jargonuyla ortaya çıkan bu sorun, yukarıda değinilen sözcüklerle birlikte geniş bir jargonun varlığını da doğrulamaktadır. Niteliksel bir araştırma yöntemi olan derinlemesine görüşmelerin kullanıldığ 1 çalışmada, eşikergenlerin iletişim dili ve bu dil yoluyla yeni kız çocuğu kültürünün araştırılmasının toplumsal bir fayda yaratacağı düşünülmektedir. Kolej öğrencileri arasında oluşan jargon, üretilen dil ve ortak kodların, yaşam tarzlarıyla karş1lıklı bağımlılık ilişkisi içinde olduğu düşünülmektedir (Alp, 2006: 12). Ayrıca çocukluğun hem görünüş hem de içerik olarak yitişinin hızlanmasının dil üzerinden çözümlenmesi “çocukları nasıl bir geleceğin beklediği" sorusunu da tartışmaya açmaktadır.

\section{Eşikergen jargonu ve Instagram}

Sözlüğe göre; jargon, küçük bir toplulukça konuşulan bozuk dil, argo olarak açıklanmaktadır (Püsküllüoğlu, 2007: 961). Ancak argo, jargon ve küfür farklı anlamlar taş1maktadır. Bir meslek grubu üyelerince dışarıdan anlaşılmaması için sözcüklerin bozulmasıyla oluş̧urulan jargon, grup dışına taşması halinde argoya dönüşmektedir. Dil türleri arasında toplumun ve kültürün özelliklerini yansıtması bakımından özel dil kategorisinde değerlendirilen argo, yapı olarak kaba sözcükten de ayrışmaktadır. Argonun halk dilinden ayrılması neredeyse imkansız bir düzeyde homojen bir yapı halini alması, onun kaba dilden tamamen ayrı bir dil düzeyi olduğunu göstermektedir (Güzel ve Karakurt, 2015: 6). Toplumun alt tabakasındaki konuşurları sebebiyle kaba ve küfürlü kelimelerin de argoya dahil edilmesi doğru değildir, çünkü argo kaba bir dil kapsamında değerlendirilse bile her kaba ya da küfürlü sözcük argo sayılmamaktadır (Sonay, 2011).

Ana dile bağlı olarak gelişen alt katmanlar özel dil şeklinde tanımlanmakta, bunlar içinde özelikle internetin gelişmesiyle kitle iletişiminin oluşturduğu jargonun iki farklı açıdan çözümlenmesi önerilmektedir:

1) Psikolojik baskıyı azaltma ya da bastırılmış duygu ve düşünceleri farklı bir yolla yansitan bir araç olarak;

2) Sosyolojik olay ve olguların oluşturduğu bir özel dil olarak (Batur, 2010: 64-66).

Eşikergenler de şifreleme olarak sayılar, kelimelerin baş harfleri ya da kalıp şeklinde geliştirilen ortak bir dil kullanmaktadır.

Ancak çevrimiçi ortamlarda kullanılan bu dil, söyleyiş bozukluğu, anlam yitimi ve dilbilgisi kurallarına uyulmadan üretilmekte, daha çok kaba dil ve küfür niteliği taşımaktadır. Teknolojik dilin günlük yaşama sızarak yaygın bir biçimde sokak dili haline gelmesi önemli bir sorun olarak değerlendirilmektedir.

Bugün eşikergenlerin sosyal medya yazışmaları farklı ve oldukça iddialı bir 
jargon doğurmuştur. Bu jargonun yayılma hızında internetin etkisi büyüktür, özellikle eşikergenler sosyal medyayla birlikte büyümüşlerdir. Her türlü kuşak tanımlamalarından imtina ile, sadece dijital nesil olarak belirtilmesi uygun görülen bu yaş aralığındaki çocukların internet kullanımında aşırıya kaçtıkları bilinmektedir. Küresel düzeyde bir dijital medya araştırması olan We Are Social ajansının bulgularına göre, Instagram kullanımda dünya altıncısı (38 milyon) Türkiye için sosyal medya kullanım süresi ortalama 3 saat, en çok kullanan yaş aralığı ise 25-34 olarak açıklanmaktadır (Wearesocial, 2020). Üstelik bu raporlamada yasal olmadığı için 13 yaş altı sosyal medya kullanımı verileri bulunmamaktadır. Sonuçta dünya nüfusunun yarısının sosyal medya kullanıyor olması nedeniyle internetin çocukların dil gelişimi üzerindeki etkisi iki farklı görüş üzerinde kümelenmektedir. Bazı araştırmalarda çevrimiçi ortamlarda bulunan çocukların dil öğrenme potansiyelinin olumlu olarak etkilendiği iddia edilirken, diğer tarafta sadece gençlere özgü bir dil halini alan dijital jargonun günlük kullanım dilinden uzaklaştırması sebebiyle çocukların dil kullanım becerilerini olumsuz yönde etkilediği savunulmaktadır (Akbulut, 2013: 58-59).

\begin{abstract}
"Konuşma dilinden ağ ortamına taşınan sözcükler, söz öbekleri ve söyleyiş biçimlerine internet ortamında yeni söyleyişler ve söylemler eklenerek bu ortamın jargonu oluşturulmaktadır. Oluşturulan bu jargonun sosyal yaşama taşınarak günlük konuşma dilinin bir parçası haline gelmesi olasıdır. Her ne kadar bu araştırmadan elde edilen bulgular böyle bir etkileşimin olup olmadığını ortaya koymada yeterli olmasa da sanal ortamlarda oluşturulan jargonun bir süre sonra günlük konuşma dilinde de kullanılmaya başlanabileceği öngörüsünde bulunulabilir. Nitekim bu araştırma kapsamında internet ortamındaki sohbetlerde kullanılan dilin gerek konuşma dilini gerekse yazılı dili etkilediği yönünde bulgulara ulaşılmıştır. Öğrenciler internet ortamında kullandıkları dilin etkisiyle hiç farkında olmadan kısaltarak yazma, kısa ve öz ifadelerle yazma, özensiz yazma, yazılı sohbetlerdeki bazı kısaltılmış ifadeleri sözlü dilde de kullanma gibi alışkanlıklar edinebilmektedir." (Akbiyık vd., 2013: 19).
\end{abstract}

Çocuklar dil gelişimi sırasında konuşma tarzını taklit yoluyla öğrenmektedir. Bugün dil kirliliğinin interneti bir habis şeklinde sarması, söyleyiş bozukluğu, yabancı sözcükle konuşma ya da diğer dilbilgisi hatalarına sebep olmakta, küçük bir kitleyle sınırlı kalması gereken özel dil ya da jargon aile içindeki kardeşler arasında, okulda, sosyal çevrede ve sokaklarda yayılmaktadır. İlk çocukluk evresinde çocuğun sesleri taklit ederek telaffuz alışkanlığ 1 bir kere yerleştikten sonra değişmesi zordur, çünkü cümle kurmada, konuşmada ve kelime anlamlarındaki hatalar ya da kelime haznesinde daralmalardan kaynaklı düzeltilmeyen tüm yanlışlar alışkınlığa yol açmaktadır (Altıok, 1971: 123-131). Ellerinde tablet ve akıllı telefonlarla büyüyen çocukların dil gelişiminin sekteye uğraması, hem toplumsal hem de bireysel düzeyde geri dönüşü olmayan hasarlar bırakmaktadır.

Dijital jargon neredeyse dünyaya hakim olmaya hazırlanırken bu kodlanmış 
basit sözcükler içinde farklı anlamlandırmalar, duygular ve olgular saklıdır. Örneğin bir eşikergen jargonu olan ölçeğimi kır özgüven aşılayıcı rol oynamaktadır. On yaşındaki bir çocuğun görünüşüyle ilgili tedirginlik, endişe ve özgüvensizlik içeren duyguları, aldığ yorum ve beğenilerdeki komplimana bağlı olarak değişmekte, pembe kalplerin sayısına ve dış görünüşe bağlı bu özgüven duygusu yitirilip yeniden kazanılan gel-gitli bir duruma dönüşmektedir (Güzel ve Cizmeci, 2018: 148). Bu durum "şöhret(imsi) kadın(sı)lı̆̆ı" olarak anlaşılan "celebrity femininity" (Genz, 2015: 556) olgusunun küçük yaşlara inmesine sebep olmakta, şöhretleştirilmiş kadınsı kimlikler kız çocuklarının seçimlerine sunulmaktadır. Kız çocuklarının 1990'lı yıllar itibariyle popüler kültürde daha belirgin hale geldiği, eşikergenliğin (tweenhood) şöhret ve kadınlığın tanrısallaştırıldığ geçici ve söylemsel bir yapı olduğu yorumlanmaktadır (Kennedy, 2018). Sanal dünyanın dilini, davranış kalıplarını ve kurallarını kullanan ve bu ekran pratiklerini okulda ya da evde taklit eden kişiler, Instaşöhret ödülüyle kamçılanmakta, bir meslek vaadi taşıyan sosyal medya fenomenliği bağımlılık yaratmaktadır.

Eşikergen (tween) ve ergen (teen) jargonu olarak iddia edilen sözlüklerde cinsellik ve uyuşturucu içeren kısaltmalar da bulunmaktadır: "Bird" (kız), "cheddar" (para/nakit), "dip" (güle güle), "bounce" (ayrılmak), "home skillet” (arkadaş), "poppins" (mükemmel), gibi asıl anlamılla hiç ilgili olmayan kelimeler, "H" (hardcorn/ sert), "BRB" (be right back/hemen döneceğim), "U" (you/sen), "PAS" (parent over shoulder/omuz üzerinden ebeveyn), "IDC" (I dont care/umurumda değil), "GYPO" (get your pants off/pantolonunu çıkar) ya da "DOC" (drug of choice/uyuşturucu seçimi) gibi kısaltmalar, "411" (bilgi), "99" (parent gone/ailem gitti) ya da "420" (marijuana/esrar) gibi sayısal kodlamalar eşikergenlerin kullandığ 1 sözcüklerden bazilarıdır (Obenschain, 2020).

Türkiye'de de "LOL”, "OMG”, "bro-sista" (erkek-kız kardeş) gibi İngilizce k1saltmalar sadece mesajlaşmalarda değil, günlük dilde de kullanılmaktadır. Ayrıca Türkçe sözcüklerden oluşan "popi” (popüler), "feno" (fenomen), "efso" (efsane) gibi kısaltmalar, "favlamak" (favorilere eklemek), "stalklamak" (gizlice takip etmek), "tbt yapmak" (throw back thursday), "mentionlamak" (bir kullanıcidan bahsetmek) gibi Türkçeleştirilen sözcükler ya da "yükselmek" (sinirlenmek), "yürümek" (asılmak), "mala bağlamak" (alıklaşmak), "ateş ediyoo", "eziklemek", "ego/duyar kasmak", "neyin kafası" gibi anlamı değiştirilen sözler, "musmutlu", "ya la", "ii”" (iyi), "bayaa" (bayağı), "çoksel" (çok güzel) gibi hece eklenen/eksiltilen sözcükler ya da, "askaam" (aşkım), "aayneen", "olaay", "güsel”, "karşim", "tatliş", "minnak" gibi söyleyiş bozukluğu oluşturan pek çok kelime kullanılmaktadır. Ayrıca çok güzel olduğunu anlatmak için "düştüm" gibi fiil olarak türetilen ve övgü içeren jargon sözcüklerin yanında, Instagram'da cinsel içerikli sözler ve küfürlü yorumlara da oldukça sık rastlanmaktadır. Eşikergen kız çocuklarına istismar, taciz ya da güzellik siber zorbalığı yine dijital dil aracıllğıyla yapılmakta, medyada bu haberlere her gün bir yenisi eklenmektedir. 


\section{Güzellik zorbalığ}

Bugün neredeyse çocuğu olan her annenin dert yandığ1 akran zorbalığı, ebeveynler kadar öğretmenler ve çocuk gelişimcilerin de odağında olan önemli sorunların başında gelmektedir. Bir davranışın zorbalık olarak nitelendirilmesi için fiziki bir güç kullanma şartı aranmamakla birlikte davranışın kişiye doğrudan ya da dolayı olarak "kasten" yapılması gerekmektedir. Alanyazında zorbalığın yüz-yüze olan biçimi geleneksel akran zorbalığı, okulda yapılanı okul zorbalığ1 ve internet ortamlarında görüleni de siber zorbalık olarak geçmektedir. Bununla birlikte bir zorbalık türü olarak araştırılması gereken güzellik zorbalığı ise güzellik hegemonyasının belki de en belirgin izlenebildiği yeni bir kavram olarak öne çıkmaktadır.

Gathers (2005); kız çocuklarında gözlemlenen zorbalık ve nedenlerini şu şekilde sirlanmaktadır:

1. Ortaöğretim kız öğrencileri açısından zorbalık, birinin üzerinde doğrudan fiziksel bir eylem gerektirmez, ifşa edilen bir sırdan bir söylentiye kadar istenilen sonuca ulaşılmasını sağlayan her şey zorbalık olabilmektedir.

2. Zorbaların eylemleri için bilinen en yaygın nedenler, öğrencilerin ırkı, dini, cinsiyeti, sosyoekonomik durumu, moda anlayışı, sosyal normdan sapma kriteri ve okuldaki tutumudur.

3. Zorba genellikle akademik başarıya değer vermemekte; ama okulda başarılı olan mağduru taciz etmeyi seçmektedir. Eğitime ya da kültürel farklılıklara değer vermediği gibi alay ettiği kişiden de üstün olduğunu göstermeye çalışmaktadır.

4. Kurbanların ev yaşamları veya diğer unsurları genellikle zorbadan çok daha yüksek ya da düşük sosyoekonomik düzeydedir. Üstte olan öğrenciler kendinden daha aşağıdaki akranlarına zorbalık yapmakta; çünkü servetlerinin tanınmasını sağlamak ya da "zengin çocuk" olmayı arzu edilir hale getirmeyi amaçlamaktadır (Gathers, 2005: 10-19).

Petric'e (2020) göre; kadınlar arasında daha yaygın olan güzellik zorbalığı, güzellik ideallerine dayanan bir zorbalık türüdür. Güzellik klişelerine uymayan ya da bu tip trendleri takip etmeyenler, takip edenler tarafindan boy, ağırlık, ten rengi ya da giysiler gibi dış görünüşle ilgili özelliklerden dolayı aşağılanmakta ve alay edilmektedir. Güzellik zorbalığı yüzünden birçok kadın makyaj yapmak, saç trendlerini takip etmek, ince bir fiziğe sahip olmak ya da moda giysiler giyinmek zorunda hissetmektedir. Ayrıca düşük benlik saygısı, çirkinlik kompleksi, sosyal kaygı, depresyon, anoreksiya nervoza ve bulimiya nervoza (yeme bozuklukları) gibi pek çok psikolojik sorunlar da yaşamaktadır (2).

İlk olarak Bill Belsey (2003) tarafından kavramsallaştırılan siber zorbalık, geleneksel akran zorbalığının bir uzantısı olarak kabul edilmektedir. Diğer yandan yüz yüze gerçekleşen akran zorbalığından farklı olarak teknoloji kullanımında bilgi ve beceri istemesi, fiziksel ve duygusal tepkilerin anlık olarak görülmemesi ve buna karşın yabancılar tarafından da izlenebilmesi gibi pek çok bileşeni içinde barındırmaktadır. 
Bir davranışın siber zorbalık olarak kabul edilmesi için 1) Kasten zarar verme niyetiyle yapılmas1; 2) Davranışın tekrar etmesi; 3) Zorbayla mağduru arasında bir güç dengesizliği bulunması gerekmektedir. Her ne niyetle yapılırsa yapılsın siber zorbalığı önleme konusunda da araştırmacılar tarafindan görüş farklılığı yaşamaktadır. Bir grup araştırmacıya göre teknolojiyi yasaklamak yerine, çocukların kişiliğini ve iletişim biçimlerini güçlendirerek zorbalıkla mücadele edilebileceği savunulmakta ya da tam tersi bu ortama zemin hazırlaması bağlamında bilgi ve iletişim teknolojileri suçlanmaktadır. Sonuç olarak siber zorbalık bütün bu teknolojilerin sağladığı kolaylıklarla kullanıcılarının kişilik özelliklerinin etkileşimi sonucunda ortaya çıkan bir davranış olarak kavramsallaşmaktadır (Tanrıkulu, 2020: 9-16).

Kız çocuklarının erkeklere oranla daha fazla siber zorbalığa maruz kaldığını ve siber zorbalık ve mağduriyetin ortaokulda doruk noktasına ulaştığını gösteren araştırmalar oldukça yaygındır. Gelişimsel olarak çocukların önce fiziksel, sonra sözel şiddet kullanmalarının sebebi dil becerisindeki gelişimle açıklanmaktadır. Çocuğun okula başlaması, konuşma ve yazıyı geliştirmesi, akran ilişkileri kurması, teknoloji kullanımında ilerlemesi sonucunda öfke biçimlerinin de ortaya çıkmaya başladığı belirtilmektedir (Özdemir, 2020: 24-42).

Okullarda akranlar arasında görülen güzellik zorbalığı sosyal medya platformlarında da yaygın olarak gözlemlenebilmektedir. Bunun için 2018 yılında Rimmel Kozmetik firması ve Cybersmile Vakfi tarafından güzellik siber zorbalığına uğrayan kadınlar için asistan hizmeti başlatılmıştır. Rimmel Londra'nın, BM istatistiklerini kullanarak, 10 ülkede 16-24 yaş aralığında, 110 bin kadınla yaptığı araştırma bulgularına göre; her dört kadından biri güzellik siber zorbalığın kurbanı olduğu ve bu kadınların yüzde 65 'inin kötü yorumlar aldıktan sonra psikolojik sorunlar yaşadığı raporlanmıştır. Ayrıca güzellik siber zorbalığından dolayı her yıl 115 milyon paylaşımın sosyal medyadan silindiği de açıklanmaktadır (Rimmellondon.com 2020).

İster güzellikle ilgili fiziksel ya da sözsel olsun isterse de gizli olarak, güzellik zorbasının kurbanına karşı uyguladığı taktikler değişse bile benzer davranış biçimleri kullanılmaktadır. İlişkisel saldırganlık, kaba davranışlar, incitmek, alay etmek, dedikodu yapmak, söylenti yaymak, isim takmak, dışlamak ya da küsmek gibi davranışlar mağdura ciddi psikolojik zararlar verebilmektedir. Zorba bir gün yakın arkadaşken, bir diğer gün selam bile vermeyecek kadar tutarsız davranabilmekte, mağduru takipten ya da gruptan çıkararak cezalandırma yoluna gidebilmektedir. Özellikle kız çocuklarında sık görülen Instagram paylaşımlarını, yorumlarını silme ya da hesaplarını kapatma gibi davranışların bir nedeninin de güzellik siber zorbalığg 1 olabileceği düşünülmelidir.

Dijital araçların dilini ana dilleri gibi konuşan ve "dijital yerliler" olarak tanımlanan neslin, (Prensky, 2001: 1) Amerika' daki ilk araştırma bulgularına göre; yüzde 34'ünün, sohbet odalarında agresif ve psikopat davranışlara maruz kalmasıyla başlayan siber zorbalık gittikçe artmaktadır (Patchin ve Hinduja, 2006; Willard, 2006; Ybarra ve Mitchell, 2004, Li, 2006; Akt. Katzer vd., 2009: 25). Sadece Instagram'da 
bir yılda milyon sayıda artan tween etiketine bakıldığında, yetişkin modellere benzeyen kız çocuklarının güzellik siber zorbalığıyla karşılaşmaya açık olduğu görülebilmektedir. Özellikle fenomen çocuklara övgü yorumları yanında yüz, boy, kilo ya da giysilerine nefret içeren yorumlar da bulunmaktadır. Ortaokul yıllarında ya da erken ergenlikte zorbalığa uğrayan çocukların ilerleyen yaşlarda duygusal çöküntü yaşayabildiği, yaşadıklarının ilişkilerine yıllarca zarar verebildiği yorumlanmaktadır (Gathers, 2005: 2). Yeni medya ve teknolojik araçlara sahiplik oranının artmasıyla birlikte kıskançlık, acımasız hisler, ve kötü bir içgüdüye sahip olmak zorbalık eylemiyle yaşam bulmakta, bu deneyim insanların üzerinde büyük travmalar yaratmaktadır (Pembecioğlu ve Irmaklı, 2019: 194). Genelde okulların bilgi teknolojilerini desteklemesi ve bu teknolojik aletlerin çocuklara getirdiği kolaylık yadsınmamakla birlikte çocuk ile teknoloji arasında alıkonamaz bir bağımlılık ilişkisi gelişmiştir. Bugün kız çocuklarının cinsel içerikli paylaşımlarla var olması istismar ve taciz vakalarındaki artışla alarm vermekte, güzellik siber zorbalığının yıkıcı etkileri intihara varıncaya kadar hayati riskler taşımaktadır.

\section{Yöntem}

$\mathrm{Bu}$ araştırmada, Glaser ve Strauss tarafından geliştirilen ve bir nitel araştırma yöntemi olan gömülü teori yaklaşımı kullanılmıştır. Veri toplama ve çözümlemenin eşzamanlı olarak yürütüldügü, süreç içinde yeni verilerek eklemlenerek araştırmanın geliştirildiği ve araştırmacıya serbestlik tanıyan gömülü teori "sürekli karşılaştırmalı analiz (constant comperative analysis)" şeklinde tanımlanmaktadır (Glaser ve Strauss, 1967). Verilerin elde edildiği derinlemesine görüşmelerin en güçlü yanı görülmeyenler hakkında bilgi edinme ve görülenler ilgili alternatif açıklama yapma firsatı tanımasıdır (Corrine, 2015: 143). 2018 yılı Mart ayında başlanılan ve bir yıl süren saha araştırmasında $22 \mathrm{kız} \mathrm{çocuğuyla} \mathrm{görüşmeler} \mathrm{yapılmıştır.} \mathrm{Amaçsal} \mathrm{(purpusive)} \mathrm{örnek-}$ leme yoluyla seçilen 8-13 yaş aralığındaki kız çocuklarının, annelerinin de izinleri dahilinde gerçekleşen görüşmelerde katılımcıların kimlik bilgileri gizlenmiştir. Araştırmacı-araştıran ilişkisinde gücün genelde asimetrik olması sebebiyle etik kodlar araştırmacıya, katılımcıların gizlilik haklarına sahip çıkma ve koruma, araştırmanın yanıltıcı yönlerini hafifletme ve karşılıklılık konusunda hassasiyet sağlamaktadır (Corrine, 2015: 236). Kaldı ki alan seçiminde en büyük zorluk çocuklarla ilgili araştırmalarda yaşanmaktadır. Bu bağlamda gerek anonimliğin korunmasına gerekse zarar vermeme etik ilkesine bağlı kalmaya özen gösterilmiştir. Diğer yanda araştırmanın sadece İstanbul ilinde yürütülmesi ve kolejde okuyan kız çocuklarını kapsaması araştırmayı sınırlamaktadır. Dolayısıyla diğer illerin ve çocuk gelişimciler gibi uzmanların da katılması suretiyle daha geniş kapsamlı araştırmalara ihtiyaç duyulmaktadır.

Araştırma verilerinin çözümlenmesinde öncelikle verilerden elde edilen örüntü ve temalara odaklanılmıştır. Diğer ifadeyle görüşmeler kodlanmış, veriler temalara ayrılarak çözümlenmiştir. Buna göre dört dilsel kod belirlenmiş ve onlarla birlik- 
te dört tema sunulmuştur. "Mean girls", "beğeni yağdırmak", "doom günüsü” ve "efso" gibi eşikergenlerin dile getirdiği ve sosyal medyada kullandıkları sözcükler, onları anlatan ya da katılımcıların yorum cümleleriyle birlikte dört başlık altında tartışılmıştır:

1. "Mean girls": Plastikler, kraliçe arı ve mağdur

2. "Ölçeğimi kır": "Beğeni yağdır kanka", "tagle beni karşim"

3. "Doom günüsü” fanatikleri (3)

4. "Efso", "popi" ve "feno"

\section{Bulgular}

\section{1. "Mean girls": Plastikler, kraliçe arı ve mağdur}

Katılımcıların yarısından fazlası tarafından okuldaki zorba, popüler, fenomen, alımlı ve güzellik düşkünü kız çocukları Mean Girls filmiyle tanımlanmıştır. Mean Girls, Türkçeye Kötü Kızlar olarak çevrilen, 2004 yapımı bir sinema filmidir. On altı yaşlarındaki Cady Heron (Lidsay Lohan) ile Regina George (Rachel McAdams) karakterleri aracılığıyla filmde, "kötü kız-iyi kız" ikilemi üretilmekte, doğal ve yapay güzellik ayrımına değinilmektedir. Filmdeki sarışın zorba karakter, bakımlı ve fit olmayı, moda giysiler ve lüks yaşamı temsil eden Regina, "Plastikler" olarak adlandırılan bir liseli grubun lideridir. Belirli bir dikte stil ve davranış altında hareket eden Plastiklerin lideri Regina, "kraliçe arı" lakabıyla çağırılmaktadır. Bu güzellik zorbaları, tuttukları günlükte arkadaşlarını aşağılamakta, dedikodu yapmakta, birbirlerini kötüleseler bile hiçbir şey olmamış gibi davranmakta, lider ne isterse yapmakta, haftanın bir günü pembe giysiler giymekte, güzelliğe ve dış görünüşe aşırı önem vermektedir.

Katılımcıların da kendi okullarındaki zorba akranlarını tanımladığı özellikler Plastiklerle örtüşmektedir. Dedikodu, kıskançlık, küçümsemek, şımarıklık ya da kabalık gibi yakıcı duygulardan, moda, marka ve lüks tutkusuna, abartılı davranışlardan grup oluşturma, zorba lidere itaat etmeye ve pasifize olmuş Plastik üyelerin davranışlarına varıncaya kadar pek çok özellik Regina ve grubuyla uyuşmaktadır:

"Mean Girls mü demek istiyorsun? Hani şu güzel olma çabası içinde, grubu ve uydusu kızlar? Böyle, şey, marka giyiniyorlar. Sonra şey, teneffüste, hadi oraya gidelim, vazgeçtim şunu yapalım, hepsi peşinde o kızın. Aslında çirkin değiller ama hareketleri bi tuhaf ya, abartı çok" (K4, Yaş: 12).

Burada güzellik, giyim ya da lüks gibi yetişkin kadınlarda görülen tutkuların küçük yaşlara inmesi narsis duyguların çocukları da sardığını göstermektedir. Tarihin hiçbir döneminde çocukların ihtiyaçlarının ilk sırayı işgal etmediği bir çağda, kız 
çocukları alışveriş merkezinde turluyor, güzellik merkezlerindeki özel paketlerden yararlanıyor, TV programlarında, dergilerde ya da internette şöhret ve lükse özendiriliyor, ev partileri düzenliyor, kısacası kitap okurken dahi narsisleştiriliyor (Twenge ve Campbell, 2015: 115-155). Arada kalmış bir yaş diliminin üyeleri eşikergenler, zaten psikolojik, biyolojik ve hormonal farklılaşmalar içinde kendilerini sürekli yetersiz hissettiği için dış görünüşünü iyileştirmeye çalışmakta, (görünümüne bağımlı hale gelen ebeveynleri gibi) takıntılı bir benlik gelişimi göstermektedir. Tam da bu evrede öz değer yıkımının belki de en vurucu darbesi mean girl ya da zorba akranından gelmektedir:

\begin{abstract}
“İlkokulda çok büyük bir olay yaşadık. Bana unutamayacağım bir şey yaşattılar, ama şimdi öyle değiller. Daha olgunlaştılar sanki. İnşallah öyledir. Mesela güzel giyindin kötü bakıyorlar. Mesela kendilerini Mean Girls zannediyor, yani kendisini havalı zannedip başkalarına kötü davranan. Kendisini grubun başı gibi görüyor, dediklerini yaptırmaya çalışıyor, bizde de var. O ne derse onu yapıyorlard1, tabi ben biliyorum başka kızlardan destek alıyordu. Ondan sonra aramızda tartışma oldu, gruptan çıktım falan... Gruptan çıktım derken, kavga ettik, sonra aynısını ben o kıza yaptım ne yaptığını anlasın diye... Şimdi ismimi sürekli çağıyor" (K1, Yaş:12).
\end{abstract}

Katılımcıların hepsinin istisnasız kız arkadaşlarıyla sorun yaşaması zorbalığın sınırlarını okuldan ayrılmak zorunda kalmaya kadar esnetmiştir. Zorba ve mağdur ilişkisinde saldırganlığa varan davranışlar, akran zorbalığı olarak alanyazında en sık tartışılan konular arasındadır. Ancak güzellik zorbalığı olarak ayrımsallaşmamakta, bu da sorunu derinlemesine analizden yoksun birakmaktadır. Akran zorbalığında yüz yüze olan ilişki modelinde güç kavramı fiziksel, sözlü veya bir grup sınıf arkadaş1 manipüle etme şeklindedir, siber zorbalıktaysa teknoloji kullanma becerisi, orantısız yaş ve tekrar eşliğinde herkese açık bir ortamda gerçekleşmektedir (Tanrıkulu, 2020:10-11). Dahası sosyal medyada güzellik siber zorbalığına maruz kalan kız çocukları sadece görünüm politikalarından ibaret yetişkin dünyasının bir parçasına dönüşmektedir. Bu minvalde katılımcılar da Mean Girls özdeşleşmesiyle zorba lider ve ona uyduluk eden üyeleri tarafindan güzellik zorbalığına maruz kalmış mağdur kimlikleri örneklemektedir. Sadece okulda değil, sosyal medyada da güzellik siber zorbalığına uğrayan eşikergenler, beğeni, yorum, izleme gibi uygulamalarda yalnızlaştırılarak ya da takipten çıkarılarak cezalandırmaktadır:

"Sadece okulda değil, bazen durup dururken like falan da yapmiyor. Ne bileyim Whatsapp gruptan veya takipten çıkarıyor, Instagram' da hikayene bile mahsus bakmıyor. Bazı kızlar habire resim, bi de hesap siliyor. Böyle işte hani yoksun gibi hissettiriyorlar. Tipik mean girl' (K3, Yaş: 13).

Bazı katılımcılar güzellik zorbasını uzak bir arkadaşı olarak örneklerken bazıları da en yakın arkadaşı olabileceğini ve bu sonuca sosyal medyadaki davranışlarına bakarak ulaştıklarını yorumlamaktadır. Genelde siber zorbaların empati, benlik saygıs1, özseverlik, ahlaki uzaklaşma, öz-disiplin, psikopati, nevrotizm, saldırganlık, dep- 
resif ruh hali gibi özelliklerle ilişkili olduğu bilinmektedir (Asıcı, 2020: 77). Mean girl olarak nam salmış olsun ya da olmasın zorba ve mağdurun bazen yer değiştirdiği durumlar da yaşanmakta, arkadaşlık bağı ve yakınlık derecesi sosyal medyadaki beğeni sayısıyla ölçülmektedir.

\section{2. "Ölçeğimi kır": "Beğeni yağdır kanka", "tagle beni karşim"}

Günümüzde basit bir video ya da hikÂye paylaşmak bile eşikergenler için arkadaşlık, özsaygl ve popülerlik barometresine dönüşmüştür. Artık Instagram, duyguların daha da vahşileştiği ve güvensizliklerin arttığ 1 bir platform işlevi görmektedir. Kız çocuklarının kraliçeliğini ilan ettiği ya da arkadaşını cezalandırdığı bir alan olarak, bir manzara fotoğrafina etiketlenip etiketlenmemek popülerliğin ya da dışlanmanın herkese açık bir işareti sayılmaktadır. Bunun izdüşümü de onur ve utanç etiketleri şeklinde paylaşımın altına düşmektedir. Arkadaşlığın göstergesi olan beğeni ve yorumlardan dolayı \#instautanç duymamak adına "ölçeğimi kır (BMS)" etiketi bir değer olarak kabul görmektedir. "Arkadaşlığın, bağlılığın, fiziksel özelliğin dürüstçe sayılarla takas edilmesinin sevgi gösterisi ölçeğimi kır etiketidir (Simmons, 2014: 1-2). Bu etiket adeta güzellik siber zorbalığına karşı bir can simidi olarak görülmektedir.

Türkiye'deki eşikergen fenomenlerin Instagram yazışmaları incelendiğinde, ölçeğimi kır jargonuna rastlanmamakta, ama beğeni takıntısını ifade eden "likelamak" sözcügünün dillerinden düşmediği görülmektedir. Nitekim bulgularda da bu istek 'beğeni yağdırmak' sözüyle ifade bulmuştur. Ayrıca "mala bağlamak" gibi argo sözcükler dışında küfürlü sözcükler de doğal yazışma stilinin bir parçası sayılmaktadır. Örneğin; "AMK” bir küfürden çok cümle sonunda kullandıkları bir bağlaç işlevi görmektedir (Yurdakul, 14 Ağustos 2013). Bir eşikergen için arkadaşları arasında paylaşımdan hemen önce beğeni anlaşması, zorbalıktan dostluğa geçişin bir göstergesi sayılmakta, aynı zamanda bu anlatım dijital jargonun normalleştirildiğini de göstermektedir:

"Ee ölçeğimi kır olarak bilmiyorum ama evet arkadaşlarım 'güsel' yazmazsa, ne bileyim işte hiç beğenmezse çok bozulurum. Yani işte şimdi 'çoksel' yaziyorlar, melek, 'tatliş', 'düştüm' falan. Böyle kiyafet, yüz ve fizik iyiyse ' $O M G$ ' yazan da var. Biz aramızda 'beğeni yağdır kanka' falan diyoruz, böyle şey bazen de bir hesap bir bakıyorsun 100 resmi likeliyor. "Oha falan, kim bu mal' diyoruz hani yani... Ama benimki dışarıya kapalı" (K17, Yaş: 10).

Fazla beğeni ve yorum almak, takipçi sayısını arttırmak gibi durumlar anonimlikten fenomenliğe giden yolun da kurallarını oluşturmaktadır. Instaşöhret, influencer (etkileyici), fashionista gibi güzellik ve şöhret üzerine kurulu kimlikler için denklem şöyledir: "Paylaşım güzelse, beğeni alır; çok takipçi etkileyici basamağına çıkarır; etkileyici olan da şöhreti yakalar." (Güzel, 2019: 81). Sosyal medya fenomeninin paylaşımları estetik, filtreli, güzel ve kusursuz olmalıdır. Zaten ölçeğimi kır da bu hırsın bir dışavurumu gibidir, çünkü sosyal medyada şöhret bir meslek olarak 
pazarlanmaktadır. $\mathrm{Bu}$ sarmalın içinde yer alan eşikergenler, ister sosyal onay için olsun isterse de fenomenlik hayaline kavuşmak için belirli bir güzellik standardını yakalamak zorundadır:

\begin{abstract}
"Yani aslında fenomen kızlar hep güzellik algısına uyan kızlar oluyor. Ben mesela okula bir tayt, bir basic tshirt giyip gittiğimde rahatsız hissediyorum kendimi. Işste sinavlarda giyinip süslenmek zor sabah sabah ya. Mean girller de çok güzel olmak için kasıyorlar işte. Birbirlerini çok kıskandıkları için diğer insanları aşağılıyorlar. Bize de yapıyorlar" (K19, Yaş:10).
\end{abstract}

Görüldüğg̈ gibi zorbadan mağdura, kız çocukları üzerinde güzel olma baskıs1 yarışmalı ve rekabetçi bir arkadaşlığa sebep olmaktadır. Kaldı ki sürekli güzelliğe odaklı bir yaşam, "rahatsızlık" ile ifade bulan eksiklik hissi duyumsatmaktadır. Beğeni yağdırmak jargonuyla ortaya çıkan bu psikolojik, sosyoloji ve ontolojik sorundan aileler de şikayetçidir. Aileler sanki ellerine bırakılmayan bir iple, ne yapacaklarını çok da bilemeden çocuklarını yönetmeye çalışmaktadır. Bu noktada bir annenin 3 yaşındaki kız çocuğu için mücadele ve rekabetin yaşandığg yıllar gelmeden, her istediğini yapmasına izin vererek onu koruyacağını düşünmesi de oldukça düşündürücüdür. Büyük kızının eve bir gün neşeli, bir diğer gün melankolik gelişini örnekleyerek kötülük ve kıskançlık yapan zorbalara karşı çocuklarını şımartarak güçlendirme taktiği gütmektedir. Oysaki bu taktiğin özsever kişiliğe davetiye çıkarması ve çocuğu "ben" pompasıyla bir lastik misali şişirmesi, Rebeka'ların da kendilerine göre haklı sebepleri olabileceğini düşündürmektedir. Ayrıca anneler farkında olmadan "sarışınlar aptal olur" şeklinde ataerkil cinsiyetçi etiketleri yeniden üreterek toplumsal cinsiyet rollerini de çocuklarına aktarmaktadır:

"Ay evet cadı gibi! Bir arkadaşım var o çok iyi ama başka bir arkadaşım var o çok gıcık. Öğretmenler aynı sınıfa koymadı bizi! Annem de, senin güzelliğini kıskanıyor, diyor" (K16, Yaş: 12).

"Sarışınım diye bazen kötü kız olarak algılanıyor. Filmi var ya, sarışın mı ne, Mean Girls gibi... Annem demişti” (K2, Yaş: 12).

Vasat hissetmektense kendine hayran olmaya verilen izin, saatli bir bomba yaratmaktadır. Çocuklarını veliaht gibi yetiştiren modern ebeveynlerin, iyi niyetle de olsa onların daha anaokulunda başlayan "ben özelim/bakın bana" şarkılarıyla şımartmaS1 aslında özseverlik epidemisine çanak tutmaktadır (Twenge ve Champbell, 2015: 121). Özsever kişilikle zorbanın benzer özelliklerine; yani misilleme, kavgayla cevap vermek, saldırganlık, strateji gütmek, dedikodu gibi olumsuz davranışların kötülükle cezalandırılmasına izin verilmesi benmerkezciliği teşvik etmektedir. Burada asıl sorun bu çocukların olgunlaştığında nasıl bir kişiliğe sahip olacağıdır. Youtube'da arkadaşlarına ne kadar güçlü olduğunu ispatlamak için sınıfın en zayıf çocuğuna dayak atarak ve dayağın videosunu paylaşarak 15 saniyelik şöhret peşinde koşan, öz sergileyerek popüler olmaya çalışan yeni bir nesil yetişmektedir. Asıl sorulması gereken her türlü ilgi çekme gösterisinde bulunan bu çocukların, 20 yaşına geldiğinde 
kendi sayfalarında teşhir ve ucuz popülerlik arayışının farkına vararak bundan vaz $\mathrm{m} 1$ geçeceği yoksa kışkırtıcı sitelerde boy göstermeye devam mı edeceğidir (Twenge ve Champbell, 2015: 407-408). Sanki tek hayali top modellikmiş gibi, rakiplerinden daha güzel olduğunu kanıtlarcasına benlik çabası içinde sosyal medyada binlerce paylaşım yapan çocukların gösterdiği bir diğer tehlike, lolita konseptinin yaşının düşmüş olmasıdır.

\title{
4.3. "Doom günüsü" fanatikleri
}

Eşikergen yaş grubunda doğum günü partileri ve özellikle davetli listeleri zorbalığın bir başka ifade biçimi olarak görülmektedir. Popüler bir partinin davetlisi olamama yoluyla mağduru incitmek amaçlanırken, zorbanın konumunu da bir kere daha pekiştirilmiş olmaktadır. Zorbalıkla dolu okul atmosferinde zorunlu birliktelikten muaf olan doğum günleri, kız arkadaşları dışlamak için firsat olarak kabul edilen bir aktiviteye dönüşebilmektedir (Gathers, 2005: 11).

\begin{abstract}
"Mean girl yok ya bizim grupta, haa okulda gıcık olduğum bi kız var. Durmadan laf çakıyo, koridorda bu arkamdan arkadaşlarına bağırarak 'Ay bu kız da işte şunu şunu yapmış, kavga çıkarmış’ diyor. Neden böyle yapıyor bilmiyorum. Sinir oluyorum. Çünkü benim anlaşamadığım bir kız vardı ben de ona öyle yapıyordum ondan olabilir. Bi kere bunun şimdi doom günüsü oldu, kendi arkadaşlarını bile çağırmadı. Sevmesem de o kızı, onun da hislerinin olduğunu biliyorum. Orada belli etmedi ama eve gidince üzülebilir, ağlayabilir? (K22, Yaş :10).
\end{abstract}

$\mathrm{Bu}$ anlatıda zorbalığın klasik davranış biçimi olan provokasyon okul koridorunda pratik edilmekte ve bir doğum günü partisinin zorbalık için de kullanıldığına göstermektedir. Bu kız çocuğunun kendisinin de zorbalık yaptığını üstü kapalı olarak geçiştirmesi, daha önce de değinilen zorba ve mağdurun yer değiştirebildiği durumunu örneklemektedir. Bir önemli detay da "doom günüsü” söz öbeğiyle, dilin yine yanlış kullanımıdır. Instagram'da şimdilik beş yüz gönderiden oluşan doomgünü etiketi bulunmakla birlikte, eşikergenler takip ettikleri mikro etkileyicilerin paylaşımlarının altına bu ifadeyi yorum olarak yazmaktadır. "Doom günüm” söz öbeği yoluyla hayranı olduğu kişiyle özel mesajlaşma talebini iletmekte, peş peşe yazdıkları "ss attım" sözüyle de mesaja kendi görüntüsünü de eklediğini belirmektedir. Geleneksel ünlü-hayran ilişkisinde ünlüden talep edilen imza, fotoğraf gibi beklentiler burada direk mesaj, ekran görüntüsü ve emojiler şekline dönüşmüştür. Nitekim yüz bin takipçiyle makro etkileyici sınıfında yer alan bir katılımeı da değişen bu dijital pratiği onaylarken "yürümek", “dm atmak" ve mikro influencer (küçük etkileyici sözleriyle de eşikergen jargonunun konuşma diline geçtiğini gerçeklemektedir:

"Ayy evet bana da doom günüm, dm attım, dm bak, ss attım yorumları çok geliyor. Yüz bin takipçim olduğu için makro influencer (orta etkileyici) oluyorum. 'O kadarı (mesajı) nasıl okuyayım karşim', diyorum, hiç anlamıyorlar. Dm'den yürüyorlar bildiğin" (K13, Yaş: 11). 
Sonuçta mağduru belki de ileri yaşlarında dahi etkileyecek derecede özgüven tahribatına neden olan zorbalık aktivitesi sadece doğum günlerinden ibaret değildir. Mezuniyet kutlaması, pijama partileri, davetler, okul gezileri, kamp ve tatiller dışında yurtdışından ithal edilen bir başka parti daha bu amaçlar için kullanılabilmektedir. Özellikle kolejli eşikergenler için popüler etkinliklerden biri de Halloween partisi ya da diğer ismiyle Cadılar Bayramıdır. Hıristiyanlarca her yıl 29 Ekim'de kutlanan Halloween partisi davetlilerin özenle seçildiği ve ölüleri korkutup kaçırmak için düzenlenen bir etkinlikten çok zorbalığın kutlamasına dönüşmüştür:

\begin{abstract}
"Okulun popüler kızı benim, e popi diye çağıranlar da oluyor... Biz her yıl evde Halloween Partisi yapıyoruz. Amerika'dan falan annemle alıyoruz k1yafetlerimi, ama ben seçiyorum ve kim gelecek ben karar veriyorum. Bu yıl şeytan olacağım. Normalde şeytanlar kadındır çünkü. Erkekler joker oluyorlar. Hmm kadınlar şeytan melek, cadı. Ben meleğim, ama şeytanım korkacaklar benden, ay çok eğlenceli. Dar elbise giyiyorum" (K8, Yaş: 9).
\end{abstract}

Burada şeytan kadın kimliğiyle toplumsal cinsiyet rolü, akran zorbalığ ve jargon kullanımı birlikte görülebilmektedir. Cadılığı şeytanlıkla özdeşleştiren ve bu cinsiyetleştirmeyi çocuk yaşta normalleştiren biri, muhtemelen yetişkin bir birey olduğunda da cinsiyet ayrımcılığının nedenini anlamayacaktır. Popülerlik ve fenomenlik hevesinin bütün katılımc1larda görülmesi de incelenmesi gereken bir başka konudur, çünkü güzellik ve şöhret bileșeni güzellik zorbalığını daha da körüklemektedir.

\title{
4.4. "Efso", "popi" ve "feno"
}

Instagram'da farklı olmak ya da fark yaratmanın en büyük özelliği paylaşımlardaki görsel şova bağlıdır. Öyle ki yine argo sözcüklere ifade edilen bu paylaşımlar; \#altgirl (alternatif kız, 3.8 milyon), \#inkedgirl(s) (dövmeli kız, 11.5 milyon) ve \#ulzzanggirl (Korece güzel yüzlü kız, 2.1 milyon) gibi etiketler altında farklı birer kadın kimliğine dönüşmüş, hepsinde ortak özellik güzellik, stil, seksilik, gösteriş ve fenomen olmak isteği şeklinde sabitlenmiştir. Sosyal medya fenomenliğinin şöhret, hayran kitlesi ve iş imkanları yaratması, onu aranılan bir olgu haline getirmiştir. Instagram'da statü, güç ve kazanç elde etmenin yolunun Instaşöhretten geçmesi, eşikergen kız çocuklarının da yetişkinlerle aynı stratejileri gütmesine neden olmuştur. Güzel ve porselen bir yüz, incecik bir beden, seksi bakışlar, yapılı saçlar, marka giysiler, makyaj ve model pozlarıyla eşikergenlerin tamamı fenomen olma istediği duymaktadır:

“Tween fenomenleri beğeniyorum. Güzel, böyle yıkılan fizikte, iyilik meleği efso kızlar var. Onlar gibi olmak isterdim. Güzel olup böyle çok iltifat alıp kötü olan, insanları kölesi yapan biri değil ama bak. Onlar güzel ama iyi. Hem güzel hem de kötü olanlar da var. Mesela güzel olup kendini çok böyle beğenen insanlara kötülük siniyor bence. Çok böyle özgüven sahibi olunca birbirlerine kötülük yapma ihtiyacı duyuyorlar" (K7, Yaş: 11). 
Hangi anlatıma yer verilirse verilsin içinde güzellik zorbalarının olması, bu çoğalan yıkıcı duygulardan yılan kız çocuklarında güzelliğin iyilikle buluşması istencini de körüklemektedir. Ancak burada nasıl olacak sorusu önemli bir ikilemi ortaya koymaktadır. Bir yanda güzellik zorbalı̆̆ının reddi, diğer yanda fenomen olma isteği bu çelişkinin önemli bir göstergesidir. Instagram'ın kız çocuklarını ideal güzellikle kuşatması ve rekabetçi bir dünyaya çekmesi, şöhret endüstrisinin kuralları ve özsever epidemisinin tüm belirtileri çocukların özgüven duygularını sarsmaktadır. Üstelik güzelliğe bulaşan kötülük, sinsilik ve zorbalık "efso" bir kamuflajla gizlenmekte; iyilik ve kötülük adeta yer değiştirmektedir:

“Zaten güzel olup kendini güzel düşünmeyenler tatliş oluyor, ama ben çok güzelim havasında onlar filmlerde kötü kız olur ya grubun başında... Onun gibi. Ama bir efso resim atıyor, Instagram'ına, böyle bin yorum falan yani” (K21, Yaş: 11).

\section{Sonuç ve tartışma}

Günlük dile yerleşen eşikergen jargonunun dil yozlaşmasına neden olduğunu gösteren bu araştırmada, aynı zamanda 8-13 yaş aralığındaki 22 kız çocuğunun kullandığı jargonun niteliği de incelenmiştir. Özellikle Covid-19 salgınıyla birlikte sosyal medyanın günlük yaşamın ayrılmaz bir parçasına dönüştüğü, yazışma dilinin kullanımının çevrimdışı ortamlarda da arttırdığı görülmektedir. Bugün sadece Instagram'da değil, WhatsApp yazışmalarında da "OMG", " $L O L$ ", "AMK", "piki” (pekiyi), "ya la", "güsel”, "karşim", "mala bağlamak", "oha falan olmak" gibi pek çok kısaltmaların, hece eklenen/eksiltilen sözcüklerin ya da söyleyiş bozukluğu oluşturan argo ve küfürlü sözcüklerin kullanılması bu dilin kimler tarafından oluşturulduğu sorusunu akla getirmektedir. Sosyal medya kullanım oranları her yıl artmakta, buna karşın yaş sınırlaması sebebiyle 13 yaşın altındaki çocuklar (sosyal medyada var olmalarına rağmen) dijital raporlarda yer almamaktadır. Bu noktada sosyal medyayı en çok kullanan yaş aralığı kategorisinin geçerliliğine de bir soru işareti düşmek gerekmektedir. Bugün sadece eşikergen etiketlerinin gösterdiği tablo, çocukların dijital jargonun oluşum sürecinde değilse bile yayılmasında katkıda bulunmalarıdır. Nitekim ülkemizde sosyal medya kullanım oranlarını neredeyse zirveye kadar götürmeye yardımcı olduğu düşünülen bu kitlenin, dijital jargonları günlük dilde de kullandığı görülmüştür.

$\mathrm{Bu}$ dilin niteliği incelendiğinde, güzellik, şöhret, özseverlik, güzellik zorbalı̆̆1, güzellik siber zorbalığı ve yozlaşma gibi kavramlarla ilişkili olduğu söylenebilmektedir. Şöhret, güzellik ve lüks yaşamın pompalandığ 1 , internete erişimin istenilen her an gerçekleştiği, oluşturulan idealin akıllı cihazlara gelen bildirimler yoluyla teşvik ve empoze edildiği, alışverişin sıradan bir pratiğe dönüştüğü ve beğenilerin dış görünüşe indirgendiği bir çağda, artık sadece kadınlar değil, kız çocukları da hızla tüketici kitlelere dönüştürülmektedir. Dolayısıyla "feno", "efso" ya da "popi” olma ideali normal- 
leşmekte, biyolojik, hormonal ya da psikolojik etkilere çok açı bir evrede, çocuklukla yetişkinliğin arasında bırakılan eşikergenler, onları karanlık bir geleceğe iten eksiklik hissiyle büyümektedir. Belki de bu yüzden Instagram'da beğeni almak bu kadar önemsenmekte, ancak ulaşılamayan bir hedef olarak konumlandırılan güzellik idealleri, takıntılı, zorba ve özsever kişiliklere davetiye çıkarmaktadır.

Kolejlerden caddelere, akran gruplarından sosyal medyaya değin böylesi rekabetçi ve yarışmalı bir ortamda güzellik zorbalığı da artmaktadır. Açıkçası bu durumdan sadece anneler ve öğretmenlerin değil, kız çocuklarının da şikayetçi olması geleceğe ümitvar bir sşık yakmaktadır. Tam da bu noktada mean girl, yani zorba bir kız çocuğundan dert yanan her mağdurun, aynı zamanda bir zorba olabileceğini de yinelemek gerekmektedir. Güç ve başarının sosyal medya fenomeni olma yoluna bağlandığı bu yeni kız çocuğu kültüründe, örneğin sıradan bir doğum günü partisi bir zorbalığa dönüşebilmekte, Halloween partisi ile cinsiyetçilik, zorbalık ve olumsuz duygular meşrulaşabilmektedir.

Sözün özü araştırmada sadece dilin değil, çocukluğun da yozlaştığı sorunu ortaya çıkmaktadır. Adeta yetişkin bir görünümden oluşan, kusursuz güzellik, moda, marka, şöhret ve lüks yaşamla özdeşleştirilen ideal kız çocuğu imgesi sosyal medya aracılığıyla daha da özendirici bir hal almaktadır. Kaldı ki Instagram'da eşikergen fenomenlerin kişisel markalama faaliyetlerini, profil hesabında menajer olarak yazan annelerinin üstleniyor olması oldukça tartışmalıdır. Daha fazla geç kalmadan, dilin, kültürün ve çocukluğun yozlaşmasının önüne set çekebilmek için öncelikle bütün annelerin bu girdaptan çıkış yolunu talep etmeleri, çocuk gelişimciler, öğretmenler, akademisyen ve bilim insanlarının projeler geliştirmesi, yeni ve yürüyen sosyal politikalar eşliğinde kamu ve özel kuruluşların harekete geçmesi ve toplumsal olarak sosyal medyanın pozitif etki yaratmak amacıyla kullanılan bir mecraya dönüştürülmesi gerekmektedir. Elbette ki toplumda tüm bireylerin, özellikle de kız kardeşlik ruhuyla kadınların kenetlenebildiği takdirde, dile, kültüre ve çocukların geleceğine sahip çıkabileceği unutulmamalıdır.

\section{Notlar:}

1. Cocuk ile ergen arasındaki eșiksel bir evrenin kesiti olan tween, ergenlik öncesi ( $p r e-t e e n / s u b$-teen) ve ergen (teen) kavramlarının genişletilmesiyle ilk olarak 1920'lerin Amerika'sında mağaza reyonlarında kullanılmıştır. Hall'un (1987) “farklı karakteristiği ve güçleri” olan 9-15 yaşları arasındaki çocukları, Paterson'un (2003) 9-14 yaşları, Ko'nun (2001) 8-12 yaşları arasındaki çocukları kapsayan tween tanımı, American Demography ve Chicago Tribune'deyse 8/9-13 yaş aralığındaki çocukları kapsadığı şeklinde ileri sürülmüştür. Yaş kategorisinden çok pazar kategorisi niteliğindeki tween tanımı, "ne biri ne de diğeri” anlamına gelen "betwixt and between" deyiminden ilham almaktadır (Güzel, 2019, s. 11-14). ,

2. Daha fazla bilgi için bkz. Ebru Güzel, Yetişkinleştirilen Çocuk Tween ve Eşikergen Kavramı, Global Media Journal, (10) 20, https://globalmediajournaltr.yeditepe.edu.tr/sites/default/files/11_ebru_guzel.pdf.

3. Ss (screenshot) atmak; ekran görüntüsünü karşı tarafa yollamak anlamına gelmektedir. Dm (direct message) direk mesaj atmak, yani Instagram'ın özel yazışma bölümünden mesaj yollamak. 


\section{Kaynakça}

Asıc1, E. (2020). Siber zorbalık ve kişilik özellikleri. Siber zorbalık, 2. Baskı (İ. Tanrıkulu. Ed.) İstanbul: An1.

Corrine, G. (2015). Nitel araştırmaya giriş, \%. Baskı, (A. Ersoy ve P. Yalçınoğlu. Çev.) İstanbul: Anı.

Glaser, B. G. and Strauss, A. L. (1967). The discovery of grounded theory: Strategies for qualitative research. New York: Aldine De Gruyter.

Güzel, E. ve Karakurt A. (2016). Dil yozlaşması ve söyleyiş bozukluğu televizyon reklamlarının göstergebilimsel analizi. Balkan ve Yakın Doğu Sosyal Bilimler Dergisi, 2 (3),1-15.

Güzel, E. ve Cizmeci E. (2018). Filtreli güzellik: Güzellik hegemonyasının gözde mekânı Instagram, güzellik kraliçeleri ve süper modeller. İstanbul: Postiga.

Güzel, E. (2019). Eşikteki çocuk: \#tween. 3. Baskı, İstanbul: Kırmızı Kedi.

Hall, C. (1987). Tween power: Youths' middle tier comes of age. Marketing and Media Decisions, 22 (October), 56-62.

Katzer C., Fetchenhauer, D. and Belschak F. (2009). Cyberbullying: Who are the victims? A comparison of victimization in internet chatrooms and victimization in school. Journal of Media Psychology, 21(1), 25-36.

Ko, M. (2001). Further fragmentation. Newsmagazine, 28 (19), 36.

Li, Q. (2006). Cyberbullying in schools. A research of gender differences. School Psychology International, 27, 157-170.

Patchin, J. W. and Hinduja, S. (2006). Bullies move beyond the schoolyard. A preliminary look at cyberbullying. Youth Violence and Juvenile Justice, 4(2), 148-169.

Pembecioğlu, N. ve Irmaklı, H. (2019). Siber zorbalık farkındalık yaratmada yerel ve küresel uygulamalar. Medya Okuryazarlığ (M. Bostanc1. Ed.) İstanbul: Nobel.

Prensky, M. (2001). Digital natives, digital immigrants. On the Horizon, 9 (5), 1-6.

Püsküllüoğlu, A. (2007). Türkçe sözlük. 6. Bask1, İstanbul: Can.

Tanrıkulu, İ. (2020). Siber zorbalık ve kavramsal konular. Siber zorbalık, 2. Baskı, (İ. Tanrıkulu. Ed.) İstanbul: An1.

Twenge, J. M. ve Campbell, W. K. (2010). Asrın vebası: Narsisizm illeti (Ö. Korkmaz. Çev.) İstanbul: Kaknüs.

Waters, M. (2004). Mean girls. Paramount Pictures.

Willard, N. E. (2006). Cyberbullying and cyberthreats: Responding to the challenge of online social cruelty, threats, and distress. Champaign: Research Press.

Ybarra, M. L. and Mitchell, K. J. (2004). Online aggressors/targets, aggressors, and targets: A comparison of associated youth characteristics. Journal of Child Psychology and Psychiatry, 45, $1308-1316$.

\section{Elektronik kaynaklar}

Akbıyık C., Karadüz A. ve Seferoğlu S. S. (2013). Öğrencilerin internet ortamında kullandıkları yazılı sohbet dili üzerine bir araştırma. Bilig, Say1: 64, ss. 01-22. (22. 07. 2020). https://dergipark.org.tr/ tr/download/article-file/234352.

Akbulut, Y. (2013). Çocuk ve ergenlerde bilgisayar ve internet kullanımının gelişimsel sonuçları. Trakya Üniversitesi Eğitim Fakültesi Dergisi, Cilt 3, Sayı 2, 53-68. (22. 07. 2020). https://www. guvenliweb.org.tr/dosya/WSBTP.pdf.

Altıok, F. (1971). Çocukta dilin oluşumu ve gelişimi. Ankara Üniversitesi Eğitim Fakültesi 
Dergisi, 4, No. 1-4, ss. 115-132. Erişim tarihi, 25. 07. 2020, http://dergiler.ankara.edu.tr/ dergiler/40/488/5728.pdf.

Alp, R. (2006). Kolej öğrencileri arasında oluşan jargon üzerine bir inceleme. Milli Folklor, Y11 18, Say1 71. (25.

07. 2020). http://repository.bilkent.edu.tr/bitstream handle/11693/23607/A\%20research\%20on\%20the\%20 Jargon $\% 20$.

Batur, Z. (2010). Kitle iletişim araçlarının oluş̧urduğu yeni bir dil katmanı: öğretmen adaylarının kullandığı kitle iletişim jargonu. Uşak Üniversitesi Sosyal Bilimler Dergisi, 3/2, 63-73, Erişim tarihi, 20. 07. 2020, https://www.pegem.net/dosyalar/dokuman/132720-20120428162336-batur-4.pdf.

Gathers, E. (2005). At the hands of the mean girls: The effects of bullying on young women in the secondary classroom. (Thesis) The University of Georgia. Erişim tarihi 10. 07. 2020, http:// citeseerx.ist.psu.edu/viewdoc/download?doi=10.1.1.507.1400\&rep=rep1\&type=pdf.

Genz, S. (2015). My job is me. Feminist Media Studies. (02. 07. 2020). file:///C:/Users/lenovo/Desktop/ aysan/kmkd/My-Job-is-Me.pdf.

Kennedy, M. (2018). Tweenhood Femininity and Celebrity in Tween Popular Culture. I. B. Tauriz (e-book).

Obenschain, C. (2020). Idk: Guide to tween slang. Howstuffworks. Erişim tarihi 02. 07. 2020, https:// lifestyle.howstuffworks.com/family/parenting/tweens-teens/guide-to-tween-slang.htm.

Paterson, P. A. (2003, June). Tweens take Over: Y Generation is the Wunderkind of Brand Marketing. TD Monthly. Retrieved May 5, 2006. Erişim tarihi 02. 07. 2020, http://www.toydirectory.com/ monthly/june 2003/Tweens_Generations.asp.

Petric, D. (2020). Beauty Bullying. Erişim tarihi 30. 07. 2020, https://www.academia.edu/42018187/ Beauty_Bullying.

Rimmel London (2020). I will not be deleted. Erişim tarihi 30. 07. 2020, https://www.cybersmile.org/wpcontent/uploads/Rimmel-Beauty-Cyberbullying-Survey.pdf.

Simmons, R. (2014). The secret language of girls on instagram. Time, erişim tarihi 18. 09. 2020, https://www.rachelsimmons.com/the-secret-language-of-girls-on-instagram/.

Sonay, H. T. (2011). Türkçede argo. Erişim tarihi 25. 07. 2020, http://www.iasj.net/ iasj?func $=$ fulltext\&aId $=37791$.

Wearesocial (2020). Digital in 2020. Erişim tarihi 25. 07. 2020, https://wearesocial.com/global-digitalreport-2020.

Yurdakul, M. (14 Ağustos 2013). Z kuşağ1 jargonu: MRB sizlere ömür, hoş geldin POPİ! Pazarlamasyon. Erişim tarihi 08. 08. 2020, https://pazarlamasyon.com/mrb-sizlere-omur-hos-geldin-popi/.

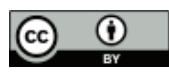

Bu eser Creative Commons Atıf 4.0 Uluslararası Lisansı ile lisanslanmıştır. (This work is licensed under a Creative Commons Attribution 4.0 International License). 